\title{
Prevalence and Molecular Characterization of Giardia duodenalis in Calves in Turkey
}

\author{
Mehmet Gultekin ${ }^{1 *}$, Kerem Ural', Nuran Aysul ${ }^{2}$, Adnan Ayan², \\ Canberk Balikci' ${ }^{1}$, Songul Toplu' $\&$ Gurkan Akyildiz ${ }^{3}$
}

\begin{abstract}
Background: Giardia duodenalis (G. duodenalis) is an ubiquitous, flagellated intestinal protozoan with major public health significance worldwide. Limited data are available on the epidemiology of G. duodenalis in dairy cattle from Turkey. Determining the zoonotic potential of the Giardia infection requires molecular characterization. The aim of the present study was to investigate the prevalence and to molecularly characterize G. duodenalis in calves less than three months of age in Aydin, Aegean region of Turkey.

Materials, Methods \& Results: The study was conducted on different dairy farms in the south-western part of the Turkey, Aegean Region, Aydin. A total of 198 Holstein Friesian calves less than three months of age, of both sexes were enrolled into the study. Faecal samples from each calf were collected manually from the rectum using a disposable latex glove. The consistency of collected samples was recorded as diarrhoeic or non-diarrhoeic. Diagnosis of G. duodenalis infection was made microscopically by detection of cysts in the faecal samples. One hundred and sixteen (58.5\%) of the 198 faecal samples were diarrheic. Giardia cysts were found in $27(23.28 \%)$ of the diarrheic samples and in $8(9.76 \%)$ of nondiarrheic samples $(P<0.05)$. The overall prevalence of giardiosis in calves was determined as $17.67 \%$. The prevalence of Giardia genotypes was identified by DNA sequence analysis of the beta-giardin gene for every PCR positive sample. The beta-giardin nested PCR assay was revealed assemblage A and sub-genotype A3 was detected in all of 35 samples (100\%). Discussion: The highest prevalence of Giardia infection in calves is reported at the age between 1 and 6 months, and the prevalence shows decreased rate from the age of 6 months. The present study was conducted in Aydin, a province of south-western Turkey in the Aegean Region, and the overall prevalence from a total of 198 dairy calves was $17.67 \%$. The prevalence rate in calves with diarrhoea was higher and reached up to $23.28 \%$, whereas it was $9.76 \%$ in non-diarrhoeic calves. A prevalence study with molecular characterization of $G$. duodenalis isolates in cattle has not yet been reported from Turkey. Molecular studies have shown that mostly assemblage E predominates in cattle, but recent studies denoted that assemblage $\mathrm{A}$ is increasingly being detected and might be more widespread than expected before. In the present study, Giardia positive samples identified with a beta-giardin nested PCR assay. The sub-genotype A3 was identified in all samples. The same sub-genotype was identified in human and dog samples from different countries. Furthermore, sub-genotype A3 was found in humans and dogs from Turkey. In this context, results of the present study suggested an important role of calves as potential reservoirs of human infections in Turkey. In conclusion, epidemiological data revealed that $G$. duodenalis infection is frequent in calves with diarrhoea in Aydin, Turkey. The presence of the potentially zoonotic sub-genotype A3 and high prevalence of Giardia infection in diarrheic calves indicated the importance of treatment and necessary preventative measures. Further studies in human and animal populations living in this region are warranted regarding the zoonotic epidemiology of Giardia duodenalis.
\end{abstract}

Keywords: calf, giardiosis, prevalence, molecular characterization. 
M. Gultekin, K. Ural, N. Aysul, et al. 2017. Prevalence and Molecular Characterization of Giardia duodenalis in

\section{INTRODUCTION}

Giardia duodenalis (G. duodenalis) is an ubiquitous, flagellated intestinal protozoan with major public health significance worldwide [18]. Giardiosis might be transmitted by the ingestion of cysts with direct or indirect contact, including human to human, animal to human or animal, waterborne and foodborne transmission $[4,40]$.

Livestock infection is common. In cattle, prevalence of giardiosis has been reported ranging from $9 \%$ to $73 \%$ with the farm prevalence rates even may rise up to $100 \%$ [18]. Chronic or reoccurring infections mostly observed in calves and cyst shedding may continue for months [34]. Clinical signs in calves include weight loss, lethargy, diarrhoea, dehydration and poor condition, although subclinical infections are frequent [16,38].

Determining the zoonotic potential of the Giardia infection requires molecular characterization $[14,28,40]$. Eight major genetic assemblages have been identified. Assemblages A and B infect both humans and animals, whereas the assemblages $\mathrm{C}$ to $\mathrm{H}$ are known as specific to animals [4]. Assemblage $\mathrm{E}$ is considered to be livestock specific and reported as most prevalent assemblage in cattle [12,29,37]. However mono or mixed infections with assemblage A [15,17,31,42,43] or assemblage B $[9,26]$ were reported in cattle from different countries Additionally, infection with more unexpected assemblages such as C, D and F were also detected in United Kingdom [33] and Spain [6] in cattle.

The number of studies related with the prevalence and molecular characterization of giardiosis in cattle is increasing $[9,19,29,42,43]$. However, only limited data is available about the epidemiology of $G$. duodenalis in dairy cattle from Turkey. Prevalence rates in calves presented between $4.1 \%$ and $14.7 \%$ from different parts of country $[11,20,21]$ whereas none of those studies recorded molecular characterization of assemblages in calves. The aim of the present study was to investigate the prevalence and molecular characterization of Giardia duodenalis in calves from Aydin region of Turkey.

\section{MATERIALS AND METHODS}

\section{Sample collection}

The study was conducted on different dairy farms in the south-western part of the Turkey, Aegean Region, Aydin. A total of 198 Holstein Friesian calves less than 3 months of age, of both sexes were enrolled into the study. The samples were withdrawn at different times of the year between March 2016 and October 2016 from several farms. Faecal samples from each calf were collected manually from the rectum using a disposable latex glove. The consistency of collected samples was recorded as diarrhoeic or non-diarrhoeic. Samples were kept on ice until laboratory examination.

\section{Microscopic examination}

Diagnosis of $G$. duodenalis infection was made microscopically by detection of cysts in the faecal samples. Faecal material was mixed through $33 \% \mathrm{ZnSO}_{4}$ solution and centrifuged at $880 \mathrm{x} g$ for 5 min [44]. Fifty $\mu \mathrm{L}$ of the supernatant was emitted on a microscope slide with Lugol iodine. The slide was microscopically examined under $400 x$ power for visualization of Giardia cysts.

\section{DNA extraction}

In order to extract the DNA, samples identified to be positive after microscopic examination of faeces were selected according to the procedure previously described by Mahdy et al. [30]. DNA extraction of the samples was achieved using QIAamp DNA Stool Mini $\mathrm{Kit}^{1}$. The extracted DNA was preserved at $-20^{\circ} \mathrm{C}$ until further analysis.

\section{Nested PCR reaction}

Following the procedure previously described by Caccio et al. [5], $\beta$-giardin gene, consisting of 753 bp fragment, was amplified using an appropriate primer. For this purpose, 10 pmol appropriate primer (G7 F5'-AAG CCC GAC GAC CTC ACC CGC AGT GC-3' forward and G759R 5'-GAG GCC GCC CTG GAT CTT CGA GAC GAC-3' reverse), $200 \mu \mathrm{M}$ of dNTPs, $1.5 \mathrm{mM} \mathrm{MgCl} 2,1 \mathrm{U}$ Taq Polymerase and $10 \mathrm{X}$ reaction buffer (500 mM Tris-HCl, pH 8.8, $160 \mathrm{mM}\left(\mathrm{NH}_{4}\right)_{2} \mathrm{SO}_{4}$ and $0.1 \%$ Tween 20$)^{2}$ and 100 ng DNA was diluted to final volume of $25 \mu \mathrm{L}$. DNA was denatured at $95^{\circ} \mathrm{C}$ for $15 \mathrm{~min}$, followed by annealing at $60^{\circ} \mathrm{C}$ for $30 \mathrm{~s}$ and by final extension for seven min at $72^{\circ} \mathrm{C}$. The DNA copies of $\beta$-giardin gene were separated using $2 \%$ agarose gel. The gel was stained with ethidium bromide and visualized with UV transillumination.

Another $511 \mathrm{bp}$ fragment of the beta-giardin gene was amplified with a suitable primer (BG1F 5 -GAACGAGATCGAGGTCCG-3 forward and BG2R 5 -CTCGACGAGTTCGTGTT-3 reverse) with a modification of the method described by Lalle et al. [26]. 
M. Gultekin, K. Ural, N. Aysul, et al. 2017. Prevalence and Molecular Characterization of Giardia duodenalis in

DNA sequence analysis of nested PCR positive samples

The assemblage of the strains was confirmed by sequencing the $511 \mathrm{bp}$ samples from both strands. For this purpose, the DNA copies obtained from PCR were purified using polyethylene glycol 4000 [39]. Sequencing was accomplished by using Big Dye-terminator chemistry ${ }^{3}$ following the instructions of the manufacturer. Briefly, the sequencing reaction was carried out in the TC-Plus ${ }^{4}$ thermocycler for $20 \mathrm{~s}$ at $96^{\circ} \mathrm{C}$ and annealing was conducted at $50^{\circ} \mathrm{C}$ for $20 \mathrm{~s}$. Finally, the extension was performed for $4 \mathrm{~min}$ at $60^{\circ} \mathrm{C}$ for 30 cycles. Genome Lab Genetic Analyzer ${ }^{3}$ was used for the analysis of sequencing reactions.

Obtained sequences were compared with reference sequences (GenBank® number: M36728 for sub-genotype A1, AY072723 for sub- genotype A2, AY072724 for sub- genotype A3, AY072725 for sub- genotype B1, AY072726 sub- genotype B2, AY072727 for sub- genotype B3, AY072728 for subgenotype B4) using by BLAST and BioEdit Sequence Alignment Editor.

\section{Statistical analysis}

Chi-square test was used to analyse the association between diarrhoea and giardiosis in calves. The $95 \%$ confidence interval was calculated for the prevalence rates. Probability values of $P<0.05$ were considered significant.

\section{RESULTS}

One hundred and sixteen (58.5\%) of the 198 faecal samples were diarrheic. Giardia cysts were found in 27 (23.28\%) of the diarrheic samples and in $8(9.76 \%)$ of non-diarrheic samples $(P<0.05)$. The overall prevalence of giardiosis in calves was determined as $17.67 \%$ (Table 1).

The prevalence of Giardia genotypes was identified by DNA sequence analysis of the beta-giardin gene for every PCR positive sample. The beta-giardin nested PCR assay was revealed assemblage A and sub-genotype A3 in all of 35 samples (100\%).

\section{DISCUSSION}

Giardiosis in cattle is associated with a high morbidity, significant production loss and potential transmission to other hosts $[1,4,18]$. Prevalence rates may vary according to the age of the animals, design of the study, diagnostic techniques, geographical location, climatological conditions and management practices $[4,18]$. Additionally, intermittent nature of the cyst shedding also influences the sensitivity of diagnosis [35]. The individual prevalence ranges from 9 to $73 \%$ and whereas the farm prevalence rates may rise up to 100 $\%$ [4,18]. The highest prevalence of Giardia infection is reported at the age between 1 and 6 months, and the prevalence shows decreased rate from the age of 6 months [41]. Therefore young animals are considered as the major source of infection [45]. In the present study, a total of 198 less than three months old dairy calves were enrolled.

Prevalence rates from different countries vary 2.2 to $14 \%$ in Poland [2], 9\% in Portugal [32], $17.4 \%$ to $31.3 \%$ in Belgium [17], 26.6\% in Spain [7], 30\% in Italy [3], up to $38 \%$ in Germany [25], $49 \%$ in Norway [23], up to $40.6 \%$ in New Zealand [14], 43.6\% in Denmark [27], up to $57 \%$ in Canada [9], up to $52 \%$ in the United States [24,41] and $58 \%$ in Australia [36]. The prevalence or spatial distribution of giardiosis in calves in Aegean region of Turkey is lacking.

Sivas is a city in central Turkey, where the prevalence of Giardia spp. in healthy asymptomatic cows and calves was determined as $1.4 \%$ and $4.1 \%$, respectively. Highest prevalence reported in 45-90 days old calves was $14 \%$ [11]. Van is an eastern city of Turkey, where a total of 231 calves less than eight months of age with diarrhoea were evaluated, and parasitological examination revealed Giardia spp. cysts in $14.7 \%$ of samples [20]. In another study from eastern part of Turkey, Giardia spp. cysts were found $9.34 \%$ of the dairy calves less than six months of age [21].

Table 1. Prevalence rates of giardiosis in calves from Aydin region of Turkey, 2016.

\begin{tabular}{ccccc}
\hline Condition & $\begin{array}{c}\text { Calves } \\
(\mathrm{n})\end{array}$ & $\begin{array}{c}\text { G. duodenalis } \\
\text { Positive }(\mathrm{n})\end{array}$ & $\begin{array}{c}\text { Prevalence } \\
(\mathrm{IC} 95 \%)\end{array}$ & Chi-square \\
\hline Diarrheic & 116 & 27 & $23.28(22.3-24.1)$ & \\
Non-diarrheic & 82 & 8 & $9.76(8.6-10.8)$ & $P=014$ \\
Total & 198 & 35 & $17.67(16.9-18.3)$ & \\
\hline
\end{tabular}


The present study was conducted in Aydin, a province of south-western Turkey in the Aegean Region, and the overall prevalence from a total of 198 dairy calves was $17.67 \%$. In the present study the prevalence rate in calves with diarrhoea was higher and reached up to $23.28 \%$, whereas it was $9.76 \%$ in non-diarrhoeic calves. There are conflicting results between the relation of giardiosis and diarrhoea [19]. However, most of the studies found a positive correlation between the occurrence of diarrhoea and Giardia infection in calves [38,39].

A prevalence study with molecular characterization of $G$. duodenalis isolates in cattle has not yet been reported from Turkey. Molecular studies have shown that mostly assemblage E predominates in cattle [14], but recent studies denoted that assemblage A is increasingly being detected and might be more widespread than expected before $[4,15,17,31]$. Distribution of assemblages according to the age has been noted in cattle. Assemblage A was mainly detected in calves whereas assemblage $\mathrm{E}$ was more frequent in older animals $[31,41]$. In a recent study from the south-eastern New York, $100 \%$ of Giardia positive specimens isolated from calves under 84 days of age were identified as assemblage A [31], similar to present results of our study. In the current study, overall prevalence of giardiosis in calves was \%17.67 (198/35) and all 35 isolates were belong to the same sub-genotype, A3. Prevalence or assemblages of $G$. duodenalis may show significant variation according to age, breed, season or location as reported in previous studies $[18,41]$.

Assemblages A and B have been linked with their potential zoonotic role $[4,36,41]$. However, the genetic structure of Giardia has been shown to be more complex than thought before by recent molecular studies [28,40]. Multilocus genotyping of the beta-giardin, SSU rRNA, glutamate dehydrogenase and triosephosphate isomerase loci have allowed to identify sub-assemblages [40,42]. Following this im- provement, sub-assemblages obtained from animal and human samples were compared and results showed that the most of the infections were not sharing identical genotypes between animal and human $[4,28,40]$. In the present study, Giardia positive samples identified with a beta-giardin nested PCR assay. The sub-genotype A3 was identified in all samples. The same sub-genotype was identified in human [26] and dog [10] samples from different countries. Furthermore, sub-genotype A3 was found in humans [8,13] and dogs [22] from Turkey. In this context, results of the present study suggested an important role of calves as potential reservoirs of human infections in Turkey.

\section{CONCLUSIONS}

In conclusion, epidemiological data revealed that Giardia duodenalis infection is frequent in calves with diarrhoea in Aydin, Turkey. The presence of the potentially zoonotic sub-genotype A3 and high prevalence of Giardia infection in diarrheic calves indicated the importance of treatment and necessary preventative measures. Further studies with multilocus genotyping in human and animal populations living in this region are warranted regarding the zoonotic epidemiology of G. duodenalis.

\section{MANUFACTURERS}

${ }^{1}$ Qiagen GmbH. Hilden, Germany.

${ }^{2}$ MBI Fermentas. Vilnius, Lithuania.

${ }^{3}$ Beckmann Coulter Inc. Porterville, California, USA.

${ }^{4}$ Techne. Staffordshire, UK.

Ethical approval. The study protocol was approved by the institutional laboratory animals ethics committee (with no: 2016/039 and date 25.02.2016). Informed written consent was obtained from all of the owners/animal care takers prior to enrolment.

Declaration of interest. The authors report no conflicts of interest. The authors alone are responsible for the content and writing of paper.

\section{REFERENCES}

1 Aloisio F., Filippini G., Antenucci P., Lepri E., Pezzotti G., Caccio S.M. \& Pozio E. 2006. Severe weight loss in lambs infected with Giardia duodenalis assemblage B. Veterinary Parasitology. 142: 154-158.

2 Bajer A. 2008. Cryptosporidium and Giardia spp. infections in humans, animals and the environment in Poland. Parasitology Research. 104(1): 1-7.

3 Berrilli F., Di Cave D., De Liberato C., Franco A., Scaramozzino P. \& Orecchia P. 2004. Genotype characterisation of Giardia duodenalis isolates from domestic and farm animals by SSU-rRNA gene sequencing. Veterinary Parasitology. 122(3): 193-199. 
M. Gultekin, K. Ural, N. Aysul, et al. 2017. Prevalence and Molecular Characterization of Giardia duodenalis in

4 Caccio S.M. 2015. Giardiasis: A zoonotic infection or not? In: Sing A. (Ed). Zoonoses-Infections Affecting Humans and Animals. New-York: Springer, pp.821-848.

5 Cacció S.M., de Giacomo M. \& Pozio E. 2002. Sequence analysis of the giardin gene and development of a PCRRFLP assay to genotype Giardia duodenalis cysts from human faecal samples. International Journal of Parasitology. 32: 1023-1030.

6 Cardona G.A., de Lucio A., Bailo B., Cano L., de Fuentes I. \& Carmena D. 2015. Unexpected finding of felinespecific Giardia duodenalis assemblage $\mathrm{F}$ and Cryptosporidium felis in asymptomatic adult cattle in Northern Spain. Veterinary Parasitology. 209(3-4): 258-263.

7 Castro-Hermida J.A., Almeida A., González-Warleta M., da Costa J.M.C., Rumbo-Lorenzo C. \& Mezo M. 2007. Occurrence of Cryptosporidium parvum and Giardia duodenalis in healthy adult domestic ruminants. Parasitology Research. 101(5): 1443-1448.

8 Cicek C. \& Sakru N. 2015. Genotyping of Giardia intestinalis isolates in the Thrace Region, Turkey. Mikrobiyoloji Bulteni. 49(4): 576-585.

9 Coklin T., Farber J., Parrington L. \& Dixon B. 2007. Prevalence and molecular characterization of Giardia duodenalis and Cryptosporidium spp. in dairy cattle in Ontario, Canada. Veterinary Parasitology. 150: 297-305.

10 Covacin C., Aucoin D.P., Elliot A. \& Thompson R.C.A. 2011. Genotypic characterisation of Giardia from domestic dogs in the USA. Veterinary Parasitology. 177(1): 28-32.

11 Degerli S., Celiksoz A., Kalkan K. \& Ozcelik S. 2005. Prevalence of Cryptosporidium spp. and Giardia spp. in cows and calves in Sivas. Turkish Journal of Veterinary Animal Science. 29: 995-999.

12 Dixon B., Parrington L., Cook A., Pintar K., Pollari F., Kelton D. \& Farber J. 2011. The potential for zoonotic transmission of Giardia duodenalis and Cryptosporidium spp. from beef and dairy cattle in Ontario, Canada. Veterinary Parasitology. 175: 20-26.

13 Ertug S., Ertabaklar H., Caliskan S., Malatyali E. \& Bozdogan B. 2016. Genotyping of Giardia intestinalis strains isolated from humans in Aydin, Turkey. Mikrobiyoloji Bulteni. 50(1): 152-158.

14 Feng Y. \& Xiao L. 2011. Zoonotic potential and molecular epidemiology of Giardia species and giardiasis. Clinics of Microbiology Review. 24(1): 110-140.

15 Feng Y., Ortega Y., Cama V., Terrel J. \& Xiao L. 2008. High intragenotypic diversity of Giardia duodenalis in dairy cattle on three farms. Parasitology Research. 103: 87-92.

16 Geurden T., Claerebout E., Dursin L., Deflandre A., Bernay F., Kaltsatos V. \& Vercruysse J. 2006. The efficacy of an oral treatment with paromomycin against an experimental infection with Giardia in calves. Veterinary Parasitology. 135(3-4): 241-247.

17 Geurden T., Geldhof P., Levecke B., Martens C., Berkvens D., Casaert S., Vercruysse J. \& Claerebout E. 2008. Mixed Giardia duodenalis assemblage A and E infections in calves. International Journal of Parasitology. 38: 259-264.

18 Geurden T., Vercruysse J. \& Claerebout E. 2010. Is Giardia a significant pathogen in production animals? Experimental Parasitology. 124(1): 98-106.

19 Gillhuber J., Pallant L., Ash A., Thompson R.A., Pfister K. \& Scheuerle M.C. 2013. Molecular identification of zoonotic and livestock-specific Giardia-species in faecal samples of calves in Southern Germany. Parasite \& Vectors. 6(1): 1 .

20 Goz Y., Altu N., Yüksek N. \& Özkan C. 2006. Parasites detected in neonatal and young calves with diarrhoea. Bulletin of the Veterinary Institute in Pulawy. 50: 345-248.

21 Gul A., Cicek M. \& Kilinc O. 2008. Prevalence of Eimeria spp., Cryptosporidium spp. and Giardia spp. in calves in the Van province. Turkiye Parazitoloji Dergisi. 32(3): 202-204.

22 Gultekin M., Ural K., Aysul N., Ayan A., Balikci C. \& Akyildiz G. 2017. Prevalence and molecular characterization of Giardia duodenalis in dogs in Aydin, Turkey. International Journal of Environmental Health Research. 27(3): 1-8.

23 Hamnes I.S., Gjerde B. \& Robertson L. 2006. Prevalence of Giardia and Cryptosporidium in dairy calves in three areas of Norway. Veterinary Parasitology. 140(3): 204-216.

24 Hoar B.R., Paul R.R., Siembieda J., Maria das Gracas C.P. \& Atwill E.R. 2009. Giardia duodenalis in feedlot cattle from the central and western United States. BMC Veterinary Research. 5(1): 1.

25 Jäger M., Gauly M., Bauer C., Failing K., Erhardt G. \& Zahner H. 2005. Endoparasites in calves of beef cattle herds: management systems dependent and genetic influences. Veterinary Parasitology. 131(3):173-191. 
M. Gultekin, K. Ural, N. Aysul, et al. 2017. Prevalence and Molecular Characterization of Giardia duodenalis in

26 Lalle M., Pozio E., Capelli G., Bruschi F., Crotti D. \& Cacció S.M. 2005. Genetic heterogeneity at the B-giardin locus among human and animal isolates of Giardia duodenalis and identification of potentially zoonotic subgenotypes. International Journal of Parasitology. 35: 207-213.

27 Langkjær R.B., Vigre H., Enemark H.L. \& Maddox-Hyttel C. 2007. Molecular and phylogenetic characterization of Cryptosporidium and Giardia from pigs and cattle in Denmark. Parasitology. 134(3): 339-350.

28 Lebbad M,. Mattsson J.G., Christensson B., Ljungström B., Backhans A., Andersson J.O. \& Svärd S.G. 2010. From mouse to moose: multilocus genotyping of Giardia isolates from various animal species. Veterinary Parasitology. 168(3-4): 231-239.

29 Lee S.H., VanBik D., Kim H.Y., Cho A., Kim J.W., Byun J.W., Oem J.K., Oh S.I. \& Kwak D. 2016. Prevalence and molecular characterisation of Giardia duodenalis in calves with diarrhoea. Veterinary Record. 178(25): 633.

30 Mahdy A.K.M., Surin J., Wan K.L., Mohd-Adnan A., Al-Mekhlafi M.S.H. \& Lim Y.A.L. 2009. Giardia intestinalis genotypes: Risk factors and correlation with clinical symptoms. Acta Tropica. 112: 67-70.

31 Mark-Carew M.P., Wade S.E., Chang Y.F., Schaaf S. \& Mohammed H.O. 2012. Prevalence of Giardia duodenalis assemblages among dairy herds in the New York City Watershed. Veterinary Parasitology. 185: 151-157.

32 Mendonça C., Almeida A., Castro A., de Lurdes Delgado M., Soares S., da Costa J.M. \& Canada N. 2007. Molecular characterization of Cryptosporidium and Giardia isolates from cattle from Portugal. Veterinary Parasitology. 147(1): 47-50.

33 Minetti C., Taweenan W., Hogg R., Featherstone C., Randle N., Latham S.M. \& Wastling J.M. 2014. Occurrence and Diversity of Giardia duodenalis Assemblages in Livestock in the UK. Transboundary and Emerging Diseases. 61(6): 60-67.

34 O’Handley R.M., Cockwill C., McAllister T.A., Jelinski T.A., Morck D.W. \& Olson M.E. 1999. Duration of naturally acquired giardiasis and cryptosporidiosis in dairy calves and their association with diarrhea. Journal of American Veterinary Medical Association. 214: 391-396.

35 O'Handley R.M., Olson M.E. \& McAllister T.A. 1997. Efficacy of fenbendazole for treatment of giardiasis in calves. American Journal of Veterinary Research. 58: 384-348.

36 O’handley R.M., Olson M.E., Fraser D., Adams P. \& Thompson R.C.A. 2000. Prevalence and genotypic characterisation of Giardia in dairy calves from Western Australia and Western Canada. Veterinary Parasitology. 90(3): 193-200.

37 O'Handley R.M. \& Olson M.E. 2006. Giardiasis and cryptosporidiosis in ruminants. Veterinary Clinics of North America Food Animal Practise. 22(3): 623-643.

38 Olson M.E., O'Handley R.M., Ralston B.J., McAllister T.A. \& Thompson R.C. 2004. Update on Cryptosporidium and Giardia infections in cattle. Trends in Parasitology. 20: 185-191.

39 Rosethal A., Coutelle O. \& Craxton M. 1993. Large-scale production of DNA sequencing templates by microtitre format PCR. Nucleic Acids Research. 21: 173-174.

40 Sprong H., Cacciò S.M. \& Van der Giessen J. 2009. Identification of zoonotic genotypes of Giardia duodenalis. PLOS Neglected Tropical Diseases. 3(12): 558.

41 Trout J.M., Santín M. \& Fayer R. 2007. Prevalence of Giardia duodenalis genotypes in adult dairy cows. Veterinary Parasitology. 147: 205-209.

42 Wang H., Zhao G., Chen G., Jian F., Zhang S., Feng C. \& Wang M. 2014. Multilocus genotyping of Giardia duodenalis in dairy cattle in Henan, China. PLoS One. 9(6): e100453.

43 Wegayehu T., Karim M.R., Erko B., Zhang L. \& Tilahun G. 2016. Multilocus genotyping of Giardia duodenalis isolates from calves in Oromia Special Zone, Central Ethiopia. Infection, Genetics and Evolution. 43: 281-288.

44 Wilson J.M. \& Hankerson F.C. 2009. Evaluation of an inhouse rapid ELISA test for detection of Giardia in domestic sheep (Ovis aries). American Association for Laboratory Animal Science. 49(6): 809-813.

45 Xiao L. \& Herd R.P. 1994. Infection patterns of Cryptosporidium and Giardia in calves. Veterinary Parasitology. 55(3): 257-262.

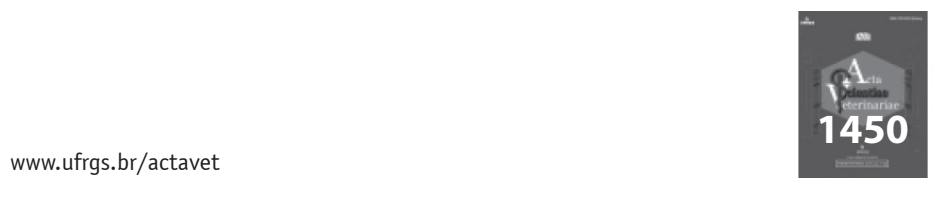

